\title{
Nature of the Non-haem Iron in Ferredoxin and Rubredoxin
}

Recently, Gillard, McKenzie, Mason, Mayhew, Peel and Stangroom ${ }^{1}$ presented optical rotatory dispersion data on non-haem iron proteins from several sources. They found that whereas the bacterial ferredoxins from Clostridium acidi-urici, C. pasteurianum and Peptostreptococcus elsdenii and the rubredoxin from $P$. elsdenii have very similar optical rotatory dispersion spectro in both the oxidized and reduced forms, these spectra differ qualitatively from that obtained with oxidized plant (parsley and spinach) ferredoxin. No data were presented on reduced plant ferredoxin, and indeed it has been reported ${ }^{2}$ that reduced plant ferredoxin has no optical activity in the visible region of the spectrum. Gillard et al. consequently suggested "that the bonding of iron in plant ferredoxin is entirely different from that in bacterial ferredoxin and rubredoxin".

Recently, we obtained measurements of both optical rotatory dispersion and circular dichroism on plant ferredoxin ${ }^{3}$ and confirmed the earlier data which Gillard et al. and earlier workers 2,4 had reported, with the exception that we were unable to find the trough at $330 \mathrm{~m} \mu$ (see ref. 1, Fig. 3). Furthermore, we extended these measurements to reduced ferredoxin; in contrast to the earlier report ${ }^{2}$, we found intense and detailed optical activity in the chemically reduced species in the visible region of the spectrum. However, this disappears slowly with a concomitant irreversible denaturation of the protein. The circular dichroism spectra indicate the presence of at least eight optically active transitions between 300 and $700 \mathrm{m \mu}$ in the oxidized and reduced proteins.

More pertinent, however, are some recent electron para. magnetic resonance (EPR) results which were not available to Gillard et al. Briefly, these can be summarized as follows. (i) Spinach ferredoxin exhibits no electron paramagnetic resonance spectrum in its oxidized form. On reduction, a spectrum typical of the $g=1.94$ class of iron proteins is obtained ${ }^{5}$. (ii) $C$. pasteurianum ferredoxin gives a variable amount of a $g=2 \cdot 0$ signal in the oxidized form and develops strong resonance in the $g=1.94$ region on reduction ${ }^{6}$. However, whereas the line-shape of spinach ferredoxin is readily understood, that of the bacterial ferredoxin is not. (iii) $C$. pasteurianum rubredoxin exhibits a strong $g=4 \cdot 3$ signal in the oxidized form and nothing on reduction, ${ }^{7,8}$. Table 1 contains a summary of this and other pertinent data.

The prediction made by Gillard et al. on the basis of their optical rotatory dispersion results, that the binding of iron in rubredoxin should be quite similar to that of 


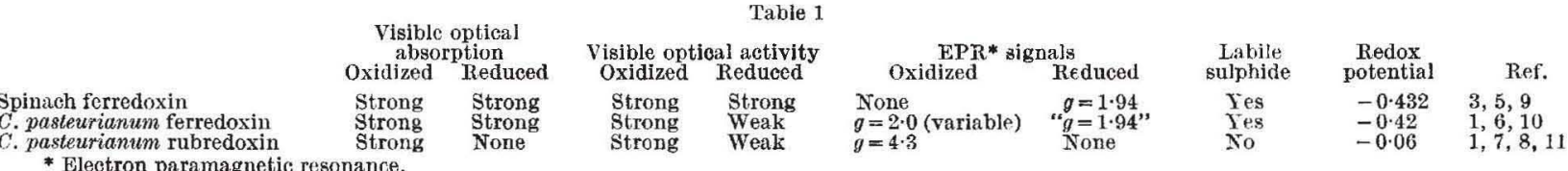

the bacterial forredoxins, is not substantiated by our electron paramagnetic resonance data. The electron paramagnetic resonance spectrum of rubredoxin is of the high-spin type found with ferrichrome and transferrin ${ }^{13}$. However, the ferredoxins have spectra which would seem to be due to low-spin iron in tetrahedral symmetry. Furthermore, the contents of Table 1 indicate that the only satisfactory way to classify these three proteins is individually. However, as has been well known ${ }^{15}$, the plant and bacterial ferredoxins have much more in common with each other than either has with rubredoxin; even so, the observed differences are reel and cannot be rationalized at this time.

Attempts to determine the ligand environment of these proteins should not be based on the application of one experimental method alone. In particular the results of Mössbauer, magnetic resonance, optical and circular dichroism spectroseopy should all be considered in our attempts to define the molecular orbital configurations of this important new elass of electron-transfor proteins.

This work was supported by the National Institutes of Health.

\section{Graham Palmeis}

Hans Brintzinger

Institute of Science and Technology,

University of Michigan, Ann Arbor, Michigan.

${ }^{1}$ Gillard, R. D., McKenzie, E. D., Mason, R., Mayhew, S. G., Peel, J. T. and Stangroom, J. E., Nature, 208, 769 (1965).

${ }^{2}$ Handler, P., Rajargopalan, K. V., and Aleman, F., quoted by Vallee, B. L. and Ulmer, $\mathrm{D}$. D. in $A$ Symposium on Non-heme Iron Proteins, edit. by San Pietro, A., 43 (Antioch Press, Yellow Springs, 1965).

${ }^{3}$ Palmer, G., and Brintzinger, II. (in preparation).

4 Ulmer, D. D., and Vallee, B. L., Biochemistry, 2, 1335 (1963).

${ }^{5}$ Palmer, G., and Sands, R. H., J. Biol. Chem., 261, 253 (1966).

${ }^{-}$Palmer, G., Sands, R. H., anư Mortensen, L. E., Biochem. Biophys. Res. Commun. (in the press).

${ }^{2}$ Palmer, G., Sands, R. H., and Mortensen, L. E. (unpublished results).

${ }^{8}$ Mower, H. F., and Piette, R. (personal communication).

${ }^{9}$ Tagawa, K., and Amon, D. I., Nature, 195, 537 (1962) ${ }^{10}$ Levenberg, W. B., Buchanan, B. B., and Rabinowitz, J. C., J. Biol. Chem.,
238, 3899 (1963).

11 Levenberg, W., and Sobel, B. E., Proc. U.S. Nat. Acad. Sci., 54, 193 (1965)

${ }^{12}$ Wickman, H. H., Klein, M. P., and Shirley, D. A., J. Chem. Phys., 42, 2113 (1965)

${ }^{13}$ Clark, J. R., and Feeney, R. E., Biochemistry, 2, 1341 (1963)

${ }^{14}$ Brintzinger, H., Palmer, G., and Sands, R. H., Proc. U.S. Nat. Acad. Sci. $55,397(1966)$

${ }^{15}$ Arnon, D. T., in A Symposium on Non-heme Iron Proteins, edit. by San Pietro, A., 137 (Antioch Press, Yellow Springs, 1965). 